\title{
La Valeur de l'œuvre littéraire, entre pôle artistique et pôle esthétique, études réunies par Patrick Voisin
}

\section{Andrea Schellino}

\section{Q OpenEdition}

1 Journals

\section{Edizione digitale}

URL: http://journals.openedition.org/studifrancesi/2334

DOI: 10.4000/studifrancesi.2334

ISSN: 2421-5856

\section{Editore}

Rosenberg \& Sellier

\section{Edizione cartacea}

Data di pubblicazione: 1 aprile 2014

Paginazione: 205-206

ISSN: 0039-2944

\section{Notizia bibliografica digitale}

Andrea Schellino, «La Valeur de l'œuvre littéraire, entre pôle artistique et pôle esthétique, études réunies par Patrick Voisin », Studi Francesi [Online], 172 (LVIII | I) | 2014, online dal 01 avril 2014, consultato il 17 septembre 2020. URL : http://journals.openedition.org/studifrancesi/2334 ; DOI : https://doi.org/ 10.4000/studifrancesi.2334

Questo documento è stato generato automaticamente il 17 settembre 2020.

\section{(c)}

Studi Francesi è distribuita con Licenza Creative Commons Attribuzione - Non commerciale - Non opere derivate 4.0 Internazionale. 


\title{
La Valeur de l'œuvre littéraire, entre pôle artistique et pôle esthétique, études réunies par Patrick Voisin
}

\author{
Andrea Schellino
}

\section{NOTIZIA}

AA. VV., La Valeur de l'œuvre littéraire, entre pôle artistique et pôle esthétique, études réunies par PATRICK VOISIN, Paris, Garnier, 2012, pp. 578.

Il presente volume collettaneo curato da Patrick voIsIN, professore di letteratura francese nelle Classes préparatoires del liceo Louis-Barthou di Pau, pone in questione una delle categorie più dibattute negli studi umanistici negli ultimi decenni: quella del valore di un'opera letteraria. È dalla nozione di valore, infatti, che dipendono numerosi problemi cruciali che si presentano in ambito estetico e artistico: lo statuto dell'autore e del lettore, la definizione di un pantheon o canone, il significato dei generi letterari, ecc. Proponendo un serrato confronto con alcune delle teorie critiche più feconde sull'argomento, i contributori sviluppano alcune esplorazioni inedite della questione del valore, attraverso quattro direttive principali (che costituiscono altrettante parti del volume): Réflexions générales, La Poésie, Le Roman e Littérature et politique.

In apertura, Patrick voIsIN (Prolégomènes: la question de la Valeur, pp. 7-20) presenta una breve messa a punto della nozione di valore e della sua rilevanza in campo letterario e critico. I principali approcci alla questione (da Bourdieu à Barthes, da Compagnon a Eco), lungi dall'aver dato una risposta definitiva, aprono la ricerca a nuove e più approfondite riflessioni. Raphaël BARONI, nel suo saggio dal titolo La valeur de l'intrigue (pp. 23-38) ripercorre i fattori che determinano il valore dell'intrigo, prendendo come esempio Derborence di Ramuz (1934). Anaïs GOUDMAND (La valeur littéraire à l'épreuve du désenchantement. Étude comparée des réflexions de Pierre Bourdieu et de Jean-Marie Schaeffer, pp. 39-54) pone a confronto le teorie critiche di Jean-Marie Schaeffer e di Pierre 
Bourdieu, sulla scia di una prospettiva relativistica del concetto di valore. Mathilde LABBÉ (Valeur éthique et valeur esthétique en littérature, pp. 55-74) propone alcune riflessioni sul conflitto tra valore etico e valore estetico delle opere letterarie. Aymen HACEN (Praxis et valeur: approche réelle et positive, pp. 75-89), attraverso l'analisi di un folto gruppo di testi (tra cui la pièce Art del 1994 di Yasmina Reza), affronta la questione del valore in funzione delle nozioni di "gusto", "fortuna" e "pratica dell'opera". Nel suo contributo ("Langue" et "littérature": une dévalorisation commune?, pp. 91-107), JeanGérard LAPACHERIE rimette in discussione le due realtà della lingua e della letteratura, prendendo spunto dagli studi recenti di William Marx (L'Adieu à la littérature. Histoire d'une dévalorisation $\mathrm{XVIII}^{e}$-XX $\mathrm{X}^{e}$ siècle, 2005) e di Gilles Philippe e Julien Piat (La langue littéraire. Une histoire de la prose en France de Gustave Flaubert à Claude Simon, 2009). Sulla lunga storia delle relazioni tra generi letterari e sulle loro contaminazioni si concentra invece Olivia voIsin in (Dé)valoriser la littérature: le texte pris dans le culte des images (pp. 109-127), che prende in considerazione la seduzione sul grande pubblico delle illustrazioni testuali. Renaud PASQUIER (Roland Barthes et la valeur introuvable. Pour un dernier tour de spirale, pp. 129-141) teorizza l'assimilazione del valore letterario all'aporia critica per eccellenza, confrontando la propria ipotesi con il percorso di Roland Barthes. Il saggio di Mathias SIEFFERT ("Le lesserez la, le povre Villon?" La valeur de la marginalité dans Le Testament de Villon, pp. 145-166) tenta di giustificare il successo dell'opera di Villon attraverso il valore dell'invenzione di un personaggio fittizio e paradossale, ideato dall'autore stesso. Da una prospettiva in parte simile muove Pascale CHIRON (La valeur testamentarie de la poésie de Villon: le texte en héritage, pp. 167-181), che nell'analisi delle implicazioni testamentarie e di trasmissione della poesia di Villon sposta il piano assiologico verso i tentativi del poeta di condizionare l'orizzonte di lettura e comprensione della sua opera. Ouafae EL MANSOURI (Les valeurs de l'œeuvre tragique: évaluation, valorisation et dévaluation d'un genre, pp. 183-198) prende in esame alcuni discorsi critici sulla tragedia del Sei e Settecento, nell'ottica dei valori attribuiti al genere tragico. La progressiva valorizzazione etica della tragedia conduce i teorici del XVIII secolo a ridimensionare drasticamente il suo valore estetico. Marc DOUGUET (Comment accroitre la valeur d'un texte de théâtre?, pp. 199-212) analizza il caso emblematico della seconda scena dell'atto II della Phèdre di Racine per mostrare il modo in cui le strutture formali di un testo possono accrescerne il valore. Nuovamente a Phèdre e all'atto della lettura è dedicato il contributo seguente di Jocelyn ROYÉ, Phèdre ou le paradoxe du spectateur (pp. 213-224). Guillaume ROBICHEZ, Thanh-Vân TON-THAT e Éric JACOBÉE, nei tre rispettivi testi (Apollinaire, poète d'Alcools: dérision ou tremblement?, pp. 225-231; Bruit et fureur poétiques du monde moderne. Alcools ou l'art de la cacophonie nouvelle, pp. 233-250; Influence du cubisme orphique et du cubisme instinctif sur les structures d'Alcools de Guillaume Apollinaire, pp. 251-269), si concentrano su Alcools di Guillaume Apollinaire e sulla sua concezione del valore e del significato della propria poesia. Bernard COMBEAUD (L'énonciation poétique comme exclamation généralisée, pp. 271-321) sviluppa l'intuizione valéryana della priorità della modalità esclamativa nel valore dell'enunciazione poetica. Con il contributo di Stéphane POUYAUD ( $L a$ valeur du roman, entre lectorat, critique et création, pp. 325-341), l'indagine sul campo valoriale della letteratura si sposta nel genere del romanzo. Cécile aLVARez ( $L a$ valeur du Paysan parvenu: du réalisme à la gaillardise, pp. 343-359) descrive la singolare posizione nella storia del genere romanzesco di Le Paysan parvenu di Marivaux. Marian BALASTRE ( $L a$ valeur emblématique de La Recherche de l'Absolu dans la Comédie Humaine, pp. 361-375) 
e Laélia VÉRON (Lecteur et lecture dans La Recherche de l'Absolu de Balzac: lire le texte à sa juste valeur, pp. 377-396) indagano il valore de La Recherche de l'Absolu nel contesto della scrittura romanzesca di Balzac. Lara POPIC, nel suo studio intitolato Valeurs et textualité chez George Sand (pp. 397-414) esamina il rapporto tra valori e testualità nelle narrazioni di George Sand. Aurélie ADLER ( $L a$ fabrique de la valeur dans les narrations françaises contemporaines. Le cas de Pierre Michon, Pierre Bergounioux, Annie Ernaux et François Bon, pp. 417-433) mette in luce come la questione del valore rappresenti una preoccupazione primaria di molti scrittori contemporanei. Sull'estetica politica presentata da Samuel Taylor Coleridge nei suoi Lay Sermons si concentra il saggio di Lucie LAGARDIÈRE (La valeur politique de la littérature chez S.T. Coleridge, pp. 437-452), mentre Sébastien BAUDoIN (Valeurs politiques et valeurs poétiques: les Méditations et Nouvelles Méditations poétiques de Lamartine, pp. 453-462) rileva il duplice binario di valori (politico/ideologici ed estetici) all'opera nelle poesie di Alphonse de Lamartine. Mohamed DJIHAD soussI ( $D u$ détour comme nécessité. Les derniers romans de José Saramago entre vertige esthétique et lucidité politique, pp. 463-475) esplora le scelte estetiche di José Saramago attraverso la considerazione dei suoi ultimi romanzi e in particolare della favola politica Ensaio sobre a Lucidez (2004). Ferroudja AlloUACHE (Les Soleils des Indépendances: une cuvre polyphonique, pp. 477-492) e Marion Mas (Épique et travestissement burlesque dans Les Soleils des Indépendances: valeurs politiques de la bâtardise, pp. 493-510) analizzano la complessità e i molti temi che trasgrediscono la scrittura romanzesca di Les Soleils des Indépendances (1968) di Ahmadou Kourouma. Conclude la miscellanea il saggio di Habib SALHA (La littérature maghrébine d'impression française, pp. 511-528), che affronta alcuni valori della letteratura francofona del Maghreb. 